\title{
Assessment of quantitative relationship between blood and PRF for periodontal surgeries
}

\author{
Maya S Indurkar ${ }^{1 *}$, Pallavi Sunil Bhailume ${ }^{2}$ \\ ${ }^{1}$ Prof., HOD \& PG Guide, Department of Periodntology, Government Dental College, Aurangabad, Maharashtra 431001 \\ ${ }^{2}$ Post Graduate Student, Department of Periodntology, Government Dental College, Aurangabad, Maharashtra 431001 \\ *Corresponding author E-mail: mayaindurkar@gmail.com
}

\begin{abstract}
Aim: The aim of study is to measure the amount of PRF obtained from different quantity of blood withdrawn from patients \& the amount of PRF and its use in different periodontal surgical procedures.

Materials and method: 15 subjects undergoing regenerative periodontal surgical therapy in whom use of PRF was indicated were included in the study. 15 subjects were divided into 3 three groups. In group A: $5 \mathrm{ml}$ of blood was withdrawn from 5 subjects. In group B: $10 \mathrm{ml}$ of blood was withdrawn from 5 subjects. In group C: $12 \mathrm{ml}$ of blood was withdrawn from 5 subjects. The steps involved were as follows:

1) Blood specimen was withdrawn from the patient,

2) The blood specimen was immediately placed in the centrifuge and was allowed to spin for 10mintes at 3000RPM,

Weight of obtained PRF was measured by using weighing scale and also length, depth \& width was measured by using UNC 15 probe. Result and Conclusion: The amount of PRF obtained depends upon the quantity of blood withdrawn. Thus, result of the present study is helpful to the operator to decide the quantity of blood to be withdrawn for particular patient to obtain desired amount of PRF.
\end{abstract}

Keywords: Class Iifurcation Defects; Intrabony; PRF, Reccesion; Vestibuloplasty

\section{Introduction}

Periodontal disease is a multifactorial, complex disease where there is an interplay of host- tissue response and bacterial infection. Any shift of the equilibrium towards the latter, causes periodontal tissue destruction and is characterized by loss of connective tissue attachment. So, the ultimate aim of periodontal therapy rendered, is resolution of inflammation and complete restoration of the lost architecture of the tissue involved, along with its function (Giannobile WV 1996, p.545-553). Various materials and procedures used for regenerative periodontal therapy includes bone grafts, soft tissue grafts, guided tissue regeneration membranes \& Platelet Rich Fibrin. One of the greatest challenge in regenerative medicine has been the development of a biomaterial, which will not only help to promote tissue healing and regeneration, but it should be also tissue compatible, easily available, clinically applicable and which aids in faster wound healing(Greenwell H 2001, p.1624-1628.). The requirements mentioned above, led to further research for newer biomaterials and techniques which would fulfil the mentioned criteria. Literature shows PRF as biomaterial, fulfilled all the requirement which are mentioned above

Ross et al were amongst the pioneers who first described about the presence and release of growth factors from platelets (.Ross R et al 1974, p. 1207-1210). Evidence shows that platelets play an important role in inflammation and wound healing. Certain growth factors and cytokines, are released after the platelets get activated which stimulate the mitogenic response during normal wound healing(Giannobile WV 1996,p. 23S-37S, V.Gupta et al 2011,p. 22 28).
Numerous techniques of autologous platelet concentrates have been developed and applied in periodontal surgery. The first generation incorporates the platelet-rich plasma while the second generation involves the platelet-rich fibrin. Platelet-rich plasma (PRP) was first identified in the early 1990s through the use of plasmapheresis and PRP sequestration (Jameson 2007). It is an autologous concentration of human platelets in a small volume of plasma (E.Marx et al. 1998, p.638-646). Although the use of platelet-rich plasma (PRP) is well documented, it has own limitations. Overcoming the limitations of first generation of platelet concentrates, a new family of platelet concentrate was developed in France. This new biomaterial, called platelet-rich fibrin (PRF) which is second generation. Platelet-rich fibrin (PRF), has been widely used to accelerate soft and hard tissue healing. Its advantages over the PRP include its ease and inexpensive method of preparation. It does not need any addition of bovine thrombin and calcium chloride, hence no hypersensitivity reactions are seen. It is autologous in nature, does not require a second spin unlike earlier other platelet concentrates (.M. Toffler et al. 2009, p. 21-32.).

Periodontal defect varies in size, to restore such defects the amount of various regenerative materials can be used. One such autogenous regenerative material is PRF, which is obtained from the blood. The requirement of PRF varies as small or large amount depending upon its use. It can be used alone as a graft material, as a membrane for guided tissue regeneration or in combination with bone graft material. The amount of PRF obtained depends upon the quantity of blood withdrawn. The present study aims to correlate the quantity of blood withdrawn and the amount of PRF obtained \& the amount of PRF and its use in different periodontal surgical procedures. 


\section{Aim}

The aim of study is to measure the amount of PRF obtained from different quantity of blood withdrawn from patients $\&$ the amount of PRF and its use in different periodontal surgical procedures.

\section{Materials and methods}

This study was conducted in the Department of Periodontology, Government Dental College and Hospital, Aurangabad in 15 subjects. The study was approved by the Institutional Ethics Committee.

Inclusion criteria

- $\quad$ Patient undergoing regenerative periodontal surgical therapy in whom use of PRF is indicated.

- Systemically healthy subjects.

- Subjects from 18years to 60 years of age.

- Willing to participate in the study.

Exclusion criteria

- $\quad$ Subjects under anti-coagulants and antiplatelets medication.

- Pregnant females.

- Medically compromised subjects.

- Smokers.

15 subjects were divided into 3 three groups

In group A: $5 \mathrm{ml}$ of blood was withdrawn from 5 subjects

In group B: $10 \mathrm{ml}$ of blood was withdrawn from 5 subjects In group C: $12 \mathrm{ml}$ of blood was withdrawn from 5 subjects Preparation:
Preparation of PRF follows the protocol developed by Choukroun et al. in Nice, France (T. R. Appel et al.2002, p. 522-528).

Requirements:

i) Table centrifuge,

ii) Dry glass test tube (without anticoagulant),

iii) Blood collection armamentarium.

The steps involved were as follows:

1) Blood specimen was withdrawn from the patient,

2) The blood specimen was immediately placed in the centrifuge and was allowed to spin for 10mintes at 3000RPM,

Due to the absence of the anticoagulant, the blood coagulates immediately upon contact with the glass tube. Initially, fibrinogen occupies the upper part of the tube, only till the circulating thrombin transforms it into a fibrin network.

The layers formed were as follows:

a) The lower fraction containing the RBCs.

b) The middle fraction containing the fibrin clot.

c) The upper fraction containing the straw-colored acellular plasma.

The upper portion of the test tube containing the acellular plasma was removed. The middle portion containing the fibrin clot was removed and is scrapped off from the lower part containing the red blood cells.

Weight of obtained PRF was measured by using weighing scale and also length, depth \& width was measured by using UNC 15 probe.

\section{Results}

The following tables present the mean length, width and thickness $\&$ weight of PRF obtained with different quantity of blood from 15 subjects.

Table 1: Showing Mean Length, Width and Thickness \& Weight of PRF Obtained from 5ml of Blood (Group A)

\begin{tabular}{|c|c|c|c|c|}
\hline QUANTITY & LENGTH & WIDTH & DEPTH & WEIGHT \\
\hline $5 \mathrm{ml}$ & $3.18 \mathrm{~cm}$ & $0.8 \mathrm{~cm}$ & $0.5 \mathrm{~cm}$ & $1.64 \mathrm{gm}$ \\
\hline QUANTITY & LENGTH & WIDTH & DEPTH & WEIGHT \\
\hline $10 \mathrm{ml}$ & $6.86 \mathrm{~cm}$ & $2.10 \mathrm{~cm}$ & $1 \mathrm{~cm}$ & $3.58 \mathrm{gm}$ \\
\hline
\end{tabular}

Table 3: Showing Mean Length, Width and Depth \& Weight of PRF Obtained from $12 \mathrm{ml}$ of Blood (Group C)

\begin{tabular}{lcccc}
\hline QUANTITY & LENGTH & WIDTH & DEPTH & WEIGHT \\
\hline $12 \mathrm{ml}$ & $7.86 \mathrm{~cm}$ & $2.14 \mathrm{~cm}$ & $1.08 \mathrm{~cm}$ & $3.9 \mathrm{gm}$ \\
\hline
\end{tabular}

Table 4: Showing Different Quantity of Blood Withdrawn \&Its Use

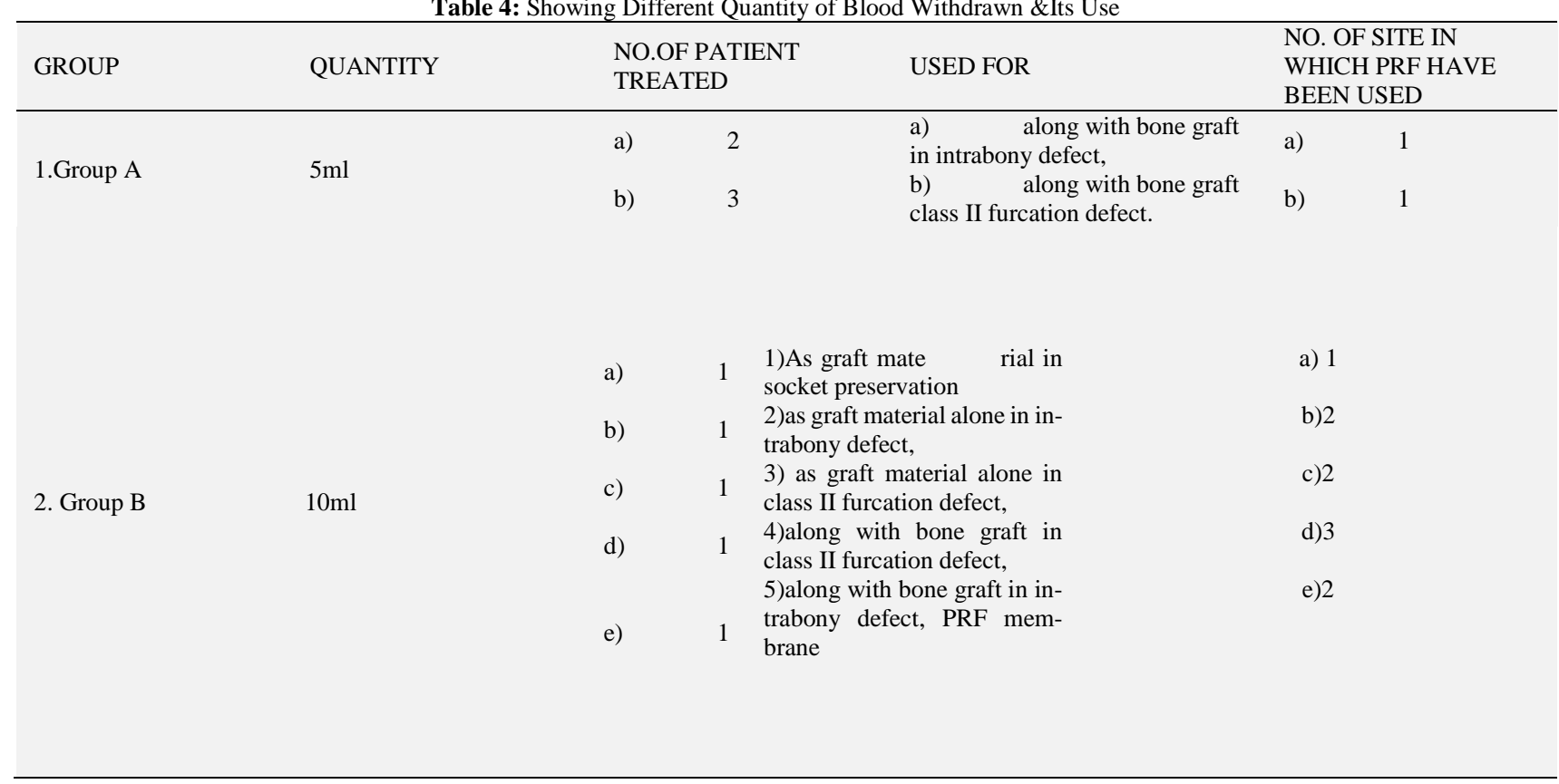




\begin{tabular}{|c|c|c|c|c|c|}
\hline \multirow{5}{*}{ 3. Group C } & \multirow{5}{*}{$12 \mathrm{ml}$} & a) & 1 & & a) 3 \\
\hline & & b) & 1 & $\begin{array}{l}\text { 1)Along with bone graft in intra- } \\
\text { bony defect, }\end{array}$ & b) 3 \\
\hline & & c) & 1 & $\begin{array}{l}\text { 2) for papilla reconstruction } \\
\text { method, }\end{array}$ & c) 1 \\
\hline & & d) & 1 & $\begin{array}{l}\text { 3) PRF dressing at the donor site, } \\
\text { 4)root coverage, }\end{array}$ & d)1 \\
\hline & & e) & 1 & 5) vestibuloplasty & e) 6 \\
\hline
\end{tabular}

\section{Discussion}

The aim of present study was to measure the amount of PRF obtained from different quantity of blood withdrawn from patients. In Group A, $5 \mathrm{ml}$ of blood was collected from 5 patients to treat total 5 defects, one in each patient. Out of 5 defects, 2 were intrabony defects and 3 were class II furcation defects. The amount of PRF obtained from $5 \mathrm{ml}$ of blood was $3.18 \mathrm{~cm}$ (length) $\mathrm{x} 0.8 \mathrm{~cm}$ (width) $\mathrm{x}$ $0.5 \mathrm{~cm}$ (depth) \& $1.64 \mathrm{gm}$ in (weight). The quantity of PRF obtained from $5 \mathrm{ml}$ of blood was not sufficient to use it alone so it was combined with DFDBA bone graft.

Choukroun et al. conducted a study in which they wanted to see the potential of using PRF in conjunction with freeze dried bone allograft (FDBA) to enhance bone regeneration in a maxillary sinus lift procedure(Choukroun J et al 2006, p.299-303). Katti et al. has published a case report on endo-perio lesion with furcation defect which has been treated by using bone graft and PRF \& concluded that there was significant reduction in pain and swelling with adequate bone fill at 3month follow up ( Katti et al. 2012, p.14-16) Simonpieri et al. suggested using a mix of PRF with a bone graft, placing in bone defects, or, in cases of immediate implants, covering it with several PRF layers, noting good clinical results(Simonpieri A et al. 2012, p.1231-1256.)

Yilmaz et al. histologically and stereologically compared the healing effects of $\beta$-TCP and PRF, alone and in combination, in standardized bone defects in pig's tibiae. The results showed that when $\beta$-TCP and PRF were used together, the newly formed bone was significantly greater than when used both separately (Yilmaz D el al. 2014, p.55-59).

Advantages of PRF along with bone graft are

i) A reduction of the volume of bone substitute,

ii) PRF act as a biologic adhesive to hold the particles together, facilitating the manipulation of the bone grafts,

iii) It may act as a "biological connector", which attracts stem cell, favors the migration of osteoprogenitor cells to the center of the graft, and provides a neo-angiogenesis,

iv) It is an economical and quick option compared with recombinant growth factors when used in conjunction with bone grafts.

In Group B, $10 \mathrm{ml}$ of blood was collected for preparation of PRF in 5 patients and total 10 sites were treated by PRF. The amount of PRF obtained from $10 \mathrm{ml}$ of blood was $6.86 \mathrm{~cm}$ (length) $\times 2.10 \mathrm{~cm}$ (width) $x 1.00 \mathrm{~cm}$ (depth) \& $3.58 \mathrm{gm}$ in (weight). This PRF was used in treating 4 intrabony defects, 5 class II furcation defects and for 1 socket preservation. Out of four intrabony defects 2 defects were treated by PRF as graft material, in 1 defects PRF was used with DFDBA bone graft, in one defect PRF was used with DFDBA bone graft and as a membrane for GTR. Out of 5 class II furcation defects, in 2 defects only PRF was used as graft material \& in 3 defects PRF was used with bone graft. In one patient PRF was for socket preservation after extraction of mandibular molar

Gassling et al. in their study concluded PRF membranes to be superior to collagen membranes as a scaffold for human periosteal cell proliferation. PRF as a regenerative material in the treatment of periodontal defects (Gassling V el al. 2010, p.543-549). Chang et al. in their case report assessed the clinical and radiographic changes in periodontal intrabony defects treated with PRF. They concluded PRF to be an effective treatment modality as the results showed that its application exhibited pocket reduction and gain in clinical attachment (.Chang Y-C et al. 2011, p.181-188).

Pradeep and Sharma, in another study on the treatment of mandibular Grade II furcation defects, showed statistically significant improvement at sites treated with PRF and OFD as compared to those with OFD alone(Pradeep AR \& Sharma A. 2011, p. 1396-1403). Pradeep and Sharma, found greater reduction in probing depth, greater gain in periodontal attachment level and greater bone fill in intrabony defects treated with PRF and open flap debridement (OFD) when compared to OFD alone(Pradeep AR \& Sharma A. 2011, p.1705-1712).

Advantage of PRF when used as a membrane for guided tissue regeneration is improved space making effect which facilitates cell events that are favorable for periodontal regeneration leading to mineralized tissue formation. PRF is also having an inherent osteoconductive and/or osteoinductive property which is beneficial for regeneration of the bone. PRF membrane has both mechanical adhesive properties and biologic functions.

PRF membrane has exhibited favorable clinical results in the treatment of periodontal infrabony defects, protecting open wounds from oral environment when the suture cannot bind the mucosal margins.

To achieve a predictable esthetic and functional restoration, it is important to preserve the dimension of alveolar ridge width and height after tooth extraction. Following extraction of tooth various patterns of bone resorption, especially on buccal side, can occur therefore socket preservation plays a very crucial role. So PRF plugs can also be used in treating the residual extraction sockets.

PRF is enriched with platelets, growth factors, and cytokines increasing the healing potential of both hard and soft tissue (Deodhar AK \& Rana RE 1997, p.52-56.). The $\alpha$-granules present in platelets contain growth factors such as PDGF, TGF, VEGF, and epidermal growth factor (Su CY et al. 2009, p.56-61). PDGF has an important role in periodontal regeneration and wound healing (Raja $S$ et al. 2009, p.82-89) and receptor for PDGF is present on gingiva, periodontal ligament, and cementum, and it activates fibroblasts and osteoblasts promoting protein synthesis (Giannobie WV et al. 1996, p.301). PDGF also functions as a chemoattractant for fibroblasts and osteoblasts in gingiva and periodontal ligament resulting in their activation.

In Group C, $12 \mathrm{ml}$ of blood was collected for preparation of PRF in 5 patients and total 14 sites were treated by PRF. The amount of PRF obtained from $12 \mathrm{ml}$ of blood was $7.86 \mathrm{~cm}$ (length) $\times 2.14 \mathrm{~cm}$ (width) x $1.08 \mathrm{~cm}$ (depth) \& $3.9 \mathrm{gm}$ (weight)]. This PRF was used as a graft material for root coverage for treating 1 site, in vesibuloplasty for treating 6 sites, in papilla reconstruction for treating 3 sites, as PRF dressing at the donor site in 1 patient after harvesting free gingival graft from the palate and also PRF along with DFDBA bone graft was used for treating 3 intrabony defects

PRF membranes have been used in conjunction with different root coverage techniques for the treatment of gingival recession. Anilkumar et al, used PRF membrane along with laterally displaced flap technique for the treatment of an isolated recession defect and reported complete root coverage with excellent gingival tissue status after 6 months(Anilkumar K et al. 2009, p.50-54). Aroca et al, on 
the other hand, reported that addition of a PRF membrane positioned under the modified coronally advanced flap (MCAF) provided inferior root coverage but an additional gain in gingival/ $\mathrm{mu}-$ cosal thickness at 6 months compared to MCAF alone(Aroca $\mathrm{S}$ et al. 2009, p.244-252).

Arunachalam et al has used PRF in the reconstruction of papilla in the maxiallry anterior region and noted optimal fill of lost interdental tissue at 3 and 6 months postoperatively (Arunachalam et al. 2012, p. 467-470.). Singhal et al has used PRF as an adjunct for vestibular extension and found that adequate depth of vestibule and width of attached gingiva was achieved using PRF as an adjunct for vestibular extension (Singhal A et al. 2015, p. 66-70.)

Kulkarni et al published case series in which they have used platelet-rich fibrin as an adjunct to palatal wound healing after harvesting free gingival graft and they had concluded that PRF as a dressing is an effective method of enhancing the healing of the palatal donor site (Kulkarni et al. 2014, p.399-402). The advantage of using of a PRF membrane to cover the fresh wound may hasten the process of wound healing by providing a stable fibrin mesh, which is more rigid than a blood clot and by providing a sustained release of growth factors and also it provides rapid hemostasis.

In all groups, patients had experienced less pain and swelling postoperatively \& also there is a good bone fill postoperatively in the treatment of class II furcation defects and intrabony defects.

\section{Conclusion}

The amount of PRF obtained depends upon the quantity of blood withdrawn. Hence this study concludes that for periodontal surgeries like root coverage, vestibuloplasty, papilla reconstruction,etc, we should collect $12 \mathrm{ml}$ of blood. PRF obtained from $12 \mathrm{ml}$ of blood was $7.86 \mathrm{~cm}$ (length) $x 2.14 \mathrm{~cm}$ (width) $x 1.08 \mathrm{~cm}$ (depth) $\& 3.9 \mathrm{gm}$ in (weight) .The amount of PRF obtained from $10 \mathrm{ml}$ of blood was $6.86 \mathrm{~cm}$ (length) $x 2.10 \mathrm{~cm}$ (width) $\mathrm{x} 1.00 \mathrm{~cm}$ (depth) $\& 3.58 \mathrm{gm}$ in (weight). PRF alone was found to be adequate for treating 2 intrabony defects in one patient and in another patient 3 class II furcation defects were treated by only PRF. Bone graft combined with PRF was adequate to treat multiple intrabony defects and class II furcation defects. The amount of PRF obtained from $5 \mathrm{ml}$ of blood was inadequate to use it alone and it has to be combined with bone graft to treat single intrabony defect and class II furcation defect .PRF obtained from $5 \mathrm{ml}$ of blood was $3.18 \mathrm{~cm}$ (length) $\mathrm{x} 0.8 \mathrm{~cm}$ (width) $\mathrm{x}$ $0.5 \mathrm{~cm}$ (depth) \& $1.64 \mathrm{gm}$ in (weight).

Thus, result of the present study is helpful to the operator to decide the quantity of blood to be withdrawn for particular patient to obtain desired amount of PRF.

\section{Footnotes}

Source of Support: Nil.

Conflict of Interest: None declare

\section{References}

[1] Giannobile WV. The potential role of growth and differentiation factors in periodontal regeneration. J Periodontol 1996;67:545-553

[2] Greenwell H. Committee on research, science and therapy, American Academy of Periodontology. Position paper: guidelines for periodontal therapy. J Periodontol 2001; 72:1624-1628. https://doi.org/10.1902/jop.2001.72.11.1624.

[3] Ross R et al. A platelet-dependent serum factor that stimulates the proliferation of arterial smooth muscle cells in vitro. Proc Natl Acad $\begin{array}{lllll}\text { Sci U S } & \text { A. 1974; 71: 1207-1210 }\end{array}$ https://doi.org/10.1073/pnas.71.4.1207.

[4] Giannobile WV. Periodontal tissue engineering by growth factors. Bone 1996; 19(Suppl. 1):23S-37S https://doi.org/10.1016/S8756 3282(96)00127-5.

[5] V.Gupta et al. "Regenerative potential of platelet rich fibrin in dentistry:literature review," Asian Journal of Oral Health and Allied Sciences 2011; vol.1,no.1:22-28
[6] E.Marx et al. "Platelet-rich plasma: growth factor enhancement for bone grafts," Oral Surgery, Oral Medicine, Oral Pathology, Oral Radiology, and Endodontics, 1998; vol. 85,638-646 https://doi.org/10.1016/S1079-2104(98)90029-4.

[7] M. Toffler et al. "Introducing Choukroun's platelet rich fibrin (PRF) to the reconstructive surgery milieu,'The Journal of Implant and Advanced Clinical Dentistry, 2009; vol. 1, no. 6, pp. 21-32.

[8] T. R. Appel et al. "Comparison of three different preparations of platelet concentrates for growth factor enrichment," Clinical Oral Implants Research, 2002; vol. 13: no. 5, pp. 522-528. https://doi.org/10.1034/j.1600-0501.2002.130512.x.

[9] Choukroun J et al: Platelet-rich fibrin (PRF): a second-generation platelet ncentrate. Part V: histologic evaluations of PRF effects on bone allograft maturation in sinus lift. Oral Surg Oral Med Oral Pathol Oral Radiol Endod 2006; 101:299-303 https://doi.org/10.1016/j.tripleo.2005.07.012.

[10] Katti, et al. : Platelet Rich Fibrin in The Treatment of Furcation Defect : A Case Report: A Journal of Clinical Dentistry;March-April 2012; Volume 04 :Issue 04:14-16

[11] Simonpieri A et al. Current knowledge and perspectives for the use of platelet-rich plasma (PRP) and platelet-rich fibrin (PRF) in oral and maxillofacial surgery part 2: Bone graft, implant and reconstructive surgery. Curr Pharm Biotechnol. 2012; 13: 1231-1256. https://doi.org/10.2174/138920112800624472.

[12] Yilmaz D el al. Effect of platelet rich fibrin and beta tricalcium phosphate on bone healing. A histological study in pigs:Acta Cir Bras 2014;29:55-59. https://doi.org/10.1590/s0102-86502014000100009.

[13] Gassling V el al. ST Platelet-rich fibrin membranes as scaffolds for periosteal tissue engineering. Clin Oral Implants Res 2010; 21:543549 https://doi.org/10.1111/j.1600-0501.2009.01900.x.

[14] Chang Y-C et al. Clinical application of platelet-rich fibrin as the sole grafting material in periodontal intrabony defects. J Dent Sci 2011; 6:181-188 https://doi.org/10.1016/j.jds.2011.05.01.

[15] Pradeep AR \& Sharma A. Autologous platelet rich fibrin in the treatment of mandibular degree II furcation defects: a randomized clinical trial. J Periodontol 2011; 82:1396-1403 https://doi.org/10.1902/jop.2011.100731.

[16] Pradeep AR \& Sharma A. Treatment of 3-wall intrabony defects in chronic periodontitis subjects with autologous platelet rich fibrin - a randomized controlled clinical trial. J Periodontol. 2011; 82(12):1705-1712. https://doi.org/10.1902/jop.2011.110075.

[17] Deodhar AK \& Rana RE. Surgical physiology of wound healing: a review. J Postgrad Med 1997; 43:52-56.

[18] Su CY et al. invitro release of growth factors from platelet rich fibrin (PRF): a proposal to optimize the clinical applications of PRF. Ora Surg Oral Med Oral Pathol Oral Radiol Endod 2009; 108:56-61. https://doi.org/10.1016/j.tripleo.2009.02.004.

[19] Raja S et al. Growth factors in periodontal regeneration. Int J Dent Hyg 2009; 7:82-89. https://doi.org/10.1111/j.16015037.2009.00380.x.

[20] Giannobie WV et al. Comparative effects of platelet- derived growth factor-BB and insulin-like growth factor-I, individually and in combination on periodontal regeneration in Macaca fascicularis. J Periodontal Res 1996; 31:301. https://doi.org/10.1111/j.16000765.1996.tb00497.x.

[21] Anilkumar K et al. Platelet-rich-fibrin: a novel root coverage approach. J Indian Soc Periodontol 2009; 13:50-54 https://doi.org/10.4103/0972-124X.51897.

[22] Aroca $\mathrm{S}$ et al. Clinical evaluation of a modified coronally advanced flap alone or in combination with a platelet-rich fibrin membrane for the treatment of adjacent multiple gingival recessions: a 6-month $\begin{array}{llll}\text { study. } & \text { J } & \text { Periodontol 2009; } & \text {; }\end{array}$ https://doi.org/10.1902/jop.2009.080253.

[23] Arunachalam et al. A novel surgical procedure for papilla reconstruction using platelet rich fibrin. Contemp Clin Dent 2012 OctDec; 3(4): 467-470. https://doi.org/10.4103/0976-237X.107443.

[24] Singhal A et al. Novel surgical procedure for vestibular extension with platelet-rich fibrin. Int J Oral Health Sci 2015; 5:66-70. https://doi.org/10.4103/2231-6027.171173.

[25] Kulkarni et al. Platelet-rich fibrin as an adjunct to palatal wound healing after harvesting a free gingival graft: A case series. J Indian Soc Periodontol 2014; 18:399-402. https://doi.org/10.4103/0972$\underline{124 X .134591 .}$ 